\title{
Osmodehydrofreezing of sensitive fruit and vegetables: Effect on quality characteristics and shelf life
}

Dermesonlouoglou, E.K., and Taoukis, P.S. (taoukis@chemeng.ntua.gr)

National Technical University of Athens, School of Chemical Engineering, Laboratory of Food Chemistry and Technology

Iroon Polytechniou, 5, 15780, Athens - Greece

\begin{abstract}
Some fruit and vegetables such as cucumber, tomato, strawberry and watermelon are not suitable for traditional freezing process, due to texture degradation, color alteration, nutritional loss, high energy costs, etc. Poor quality of these frozen tissues can significantly be improved by means of the cryoprotection accomplished by the pre-osmotic dehydration. The application of osmotic pre-treatment of fresh tissue with alternative osmotic solutes, oligofructose and a high-DE maltodextrin, at mild temperature $\left(35^{\circ} \mathrm{C}\right)$ caused substantial water loss and solid enrichment. Based on the comparative kinetic study of the quality degradation, the protective effect of both osmotic solutes on vitamin $\mathrm{C}$, lycopene and color was demonstrated. The obtained sugar enrichment and partial water removal improved the sensory characteristics of treated samples (attractive appearance: bright color, good texture and pleasant taste) when compared to untreated ones. The untreated samples suffered from a detrimental texture and taste deterioration during storage.
\end{abstract}

Keywords: osmotic-dehydration, freezing, quality, cucumber, strawberry, tomato, watermelon

\section{Introduction}

The demand for healthy, natural and tasty processed fruits continuously increases, not only for finished products, but also for ingredients to be included in complex foods such as icecreams, cereals, dairy, confectionery and bakery products. Over the last few decades wide prospects for osmotic dehydration (OD) have arisen as a pre-treatment in combined techniques. These processes use a sequence of technological steps to achieve controlled changes of the original properties of the raw material. Partial dehydration allows structural, nutritional, sensory and other functional properties of the raw material to be modified (Torreggiani and Bertolo, 2001).

The differentiating feature of OD, compared to other dehydration processes, is the penetration of solutes into the food material. So, it is possible, to a certain extent, to change the food system formulation, making it more suitable for further processing by (a)adjusting the physico-chemical composition of food by reducing water content, or adding water activity lowering agents, (b)incorporating ingredients or additives with antioxidant, or other preservative properties into the food, (c)adding solutes of nutritional or sensory interest, and (d)providing a large range of food consistency (Torreggiani and Bertolo, 2001).

OD of fruit and vegetables is achieved by placing the solid food, whole or in pieces, in a hypertonic solution (sugar and/or salt) with a simultaneous counter diffusion of solutes from the osmotic solution into the tissue. The water flow outside the cell is accompanied by the simultaneous counter diffusion of solutes from the concentrated solution into the tissue. Solutes, inherent in the cells, can, to a small extent leach out, since the cell membrane is not perfectly selective. Several parameters such as the cultivar used, temperature of the process, the composition and the concentration of the osmotic solutes in the osmotic solution, the specific characteristics of the food item, mixing parameters, etc influence significantly the 
mass transfer phenomena. A number of publications have described the role of these factors on the mass exchanges (Torreggiani, 1993).

Water loss and solid gain are mainly controlled by the raw material characteristics, certainly influenced by the possible pre-treatments. The great variability observed among the different fruits is mostly related to the tissue compactness (Giangiacomo, 1987), initial insoluble and soluble solid content (Lenart and Flink, 1984a,b), intercellular spaces, presence of gas, ratio between the different pectic fractions (water soluble pectin and propectin) (Forni et al., 1986), gelification level of pectin and enzymatic activity (Giangiacomo, 1987) of the fruit.

Dehydration pre-freeze treatments are a useful tool to reduce or avoid the detrimental phenomena of loss of cellular structure and chemical actions of freezing on fruit tissues (Huxsoll, 1982). Partial water removal from the food, prior to the freezing process, leads to the concentration of cytoplasmatic components within the cells, to the depression of the freezing point and to a consequent increase of supercooling and microcrystallization. There is a lower ratio of ice crystals to unfrozen phase, with a consequent reduction of structural and sensory characteristics. There is vast literature that indicates the usefulness of partial water removal prior to freezing, referring to numerous species of fruits (Torreggiani et al., 1995). The combined technique of dehydrofreezing has proved to be useful even to improve the quality of a delicate tissue such as that of strawberry (Sormani et al., 1999).

Additional advantages of partially concentrating fruits and vegetables prior to freezing include lower refrigeration load during freezing, savings in packaging and distribution costs, and higher product quality because of the marked reduction of structural collapse and dripping while thawing.

OD treatment using selective solutes can also allow cryoprotection of the cell during freezethawing (Tregguno and Goff, 1996). Addition of cryoprotectants and cryostabilizers in the formulation changes the glass transition temperature of the maximally cryo-concentrated food liquid phase and the freezable water content leading to higher cellular tissue integrity (Vidales et al., 2001).

In most published work, the process of OD is applied with carbohydrates such as sucrose, corn syrup, glucose, fructose, and salts such as sodium chloride $(\mathrm{NaCl})$, calcium chloride $\left(\mathrm{CaCl}_{2}\right)$ and their mixture. In this study, alternative osmotic agents were studied for pretreatment of frozen fruit and vegetables. Oligofructose, trehalose and a high-DE maltodextrin were used in the osmotic solutions, combined with $\mathrm{NaCl}$ and $\mathrm{CaCl}_{2}$. The aim was to use nonconventional, low molecular weight carbohydrates of special functional and/or nutritional characteristics, that do not alter significantly the sensory characteristics of the osmopreconcentrated tissue. Oligofructose is a non-digestible oligosaccharide, with exceptional dietary fiber properties and prebiotic activity (Rao, 2001). Trehalose, a non-reducing dissacharide has recently received much attention, owing to its protective role during freezing of membranes and proteins (Ferrando and Spiess, 2001).

The scope of the study was to investigate the effect of pre-treatment on (a)the mass transfer during osmotic dehydration of fresh tissue, and (b)the quality characteristics of frozen tissue during storage. Sensitive fruit and vegetables selected for the osmo-dehydrofreezing were cucumber, tomato, strawberry, and watermelon.

\section{Materials and Methods \\ Osmotic pre-treatment}

The studied fruit and vegetables were cucumbers, tomatoes, strawberries and watermelon. Before each experiment foods were washed, sorted (peeled, or/not) and cut into flat slices, quarters, halves or cylinders depending on the initial shape of the food material. Food samples (cucumber slices, tomato quarters, strawberry halves, and watermelon cylinders) were osmodehydrated in syrups containing $56.5 \%(\mathrm{w} / \mathrm{w})$ of the selected carbohydrate, $3.5 \% \mathrm{NaCl}$ and 
$1.5 \% \mathrm{CaCl}_{2}$. The carbohydrates were a high-DE maltodextrin (GLUCIDEX $^{\circledR} 47$, Roquette, France) and oligofructose (RAFTILOSE ${ }^{\circledR} \mathrm{P} 95$, Orafti, Belgium). The ratio of the volume of the samples to that of the medium was maintained at 1:5. The osmotic step was conducted at temperature $35^{\circ} \mathrm{C}$ for 60 min time (apart from the strawberry case where the OD time was 150 $\mathrm{min}$ ). The conditions of the osmotic dehydration and the composition of the osmotic solutions were selected based on previous comparative studies of alternative osmotic solutes with each material (Dermesonlouoglou et al., 2003 $3^{\mathrm{a}, \mathrm{b}}$ and Dermesonlouoglou et al., 2006 ${ }^{\mathrm{a}, \mathrm{b}}$ ). After osmotic treatment, food samples were rinsed, blotted with paper to remove surface solution, and weighed. The samples were dried in an oven at temperature $110^{\circ} \mathrm{C}$ for $24 \mathrm{~h}$ to estimate water content (WTB BINDER 7200, Type E53, Tuttlingen, Germany). The moisture and solid content were expressed as $\mathrm{g}$ of water/g of initial dry solids and $\mathrm{g}$ of solids/g of initial dry solids, respectively.

\section{Calculation of water loss and solid gain}

Water loss (WL), solid gain (SG) and WL/SG undergone by food samples during the osmotic pre-treatment were expressed as \% (wt/wt) of initial dry weight of foods according to the following equations (Panagiotou et al., 1999):

$\mathrm{WL}=\frac{\left(\mathrm{M}_{0}-\mathrm{m}_{0}\right)-(\mathrm{M}-\mathrm{m})}{\mathrm{m}_{0}} \quad(\mathrm{~g}$ of water $/ \mathrm{g}$ initial dry matter $)$

$\mathrm{SG}=\frac{\mathrm{m}-\mathrm{m}_{0}}{\mathrm{~m}_{0}}(\mathrm{~g}$ of total solids/g initial dry matter $)$

where $\mathrm{M}_{0}$ is the initial mass of fresh vegetable before the osmotic treatment, $\mathrm{M}$ is the mass after time $t$ of osmotic treatment, $m$ is the dry mass after time $t$ of osmotic treatment and $m_{0}$ is the initial dry mass of fresh vegetable.

\section{Freezing}

Osmodehydrated food samples were rapidly frozen at temperature $-40^{\circ} \mathrm{C}$ (Sanyo MIR 553, Sanyo Electric Co, Ora-Gun, Gunma, Japan), packed in pouches of laminate film used for commercial frozen vegetable products $[20 \mathrm{~m}$ bio-oriented polypropylene (BOPP)-48 m polyethylene (PE) with a water-vapour transmission rate (WVTR) $<6 \mathrm{~g} / \mathrm{m}^{2} * \mathrm{~d}$ ], and kept at $40^{\circ} \mathrm{C}$ for a short period of time before frozen storage experiments. Some samples were conventionally frozen (the untreated samples) so as to compare them with the dehydrofrozen ones.

\section{Frozen storage experiments}

Packages of pretreated and untreated samples were stored in controlled temperature cabinet (Sanyo MIR 153, Sanyo Electric Co, Ora-Gun, Gunma, Japan) at constant temperature $-20^{\circ} \mathrm{C}$ and monitored by type T thermocouples. Samples were obtained at 3,6 and 12 months time at each temperature so as to estimate their quality and sensory characteristics. Measurements of the quality indices of all groups of products, either dehydrofrozen, or conventionally frozen, were conducted.

\section{Physico-chemical analyses}

Colour measurements (6-8 replicates) were conducted using a colourimeter (CR-200 Minolta Chromameter ${ }^{\circledR}$, Minolta Co., Chuo-Ku, Osaka, Japan) to obtain CIELab values [L (illuminance), a (red saturation index) and b (yellow saturation index)] values. Samples were coded, placed on appropriately designed tray and three replicants of each measurement were conducted.

Texture of thawed samples was measured using a texture analyzer (MODEL TA-XT2i, Stable Micro Systems, Godalming, Surrey, U.K.). The maximum force required to compress the 
sample (3 replicates) to a depth of $1 / 3 \mathrm{~mm}$ of the initial on a non-lubricated flat platform using a knife probe was recorded by the texture analyzer and used as a measure of the product firmness.

For tissue analysis, samples were ground with mortar and pestle to reduce particle size and foaming, then homogenized. Duplicate puree samples were placed on an Atago hand-held refractometer to determine soluble solids content (Atago Co., Osaka , Japan). Total solids content was determined by drying at $110^{\circ} \mathrm{C}$ for $24 \mathrm{~h}$. Water activity of the pureed samples was measured using a Hygroscope equipment (Rotronic AG, AM3+AwVD, Bassersdorf, Switzerland) at $25^{\circ} \mathrm{C}$.

Vitamin C (L-ascorbic acid) was determined by a high performance liquid chromatography method (HP Series 1100 instrumentation: quaternary pump, vacuum degasser, a Rheodyne 20 $\mu \mathrm{l}$ injection loop and a Diode-Array Detector, controlled by HPChemStation software) on a Hypersil ODS column $(250 * 4.6 \mathrm{~mm})$, eluting with HPLC grade water (Merck, Darmstadt, Germany) with metaphosphoric acid to $\mathrm{pH} 2.2$, coupled with the detector at an absorbance of $245 \mathrm{~nm}$, according to Giannakourou and Taoukis (2002). All measurements were conducted in duplicate. The results from chromatographs were translated in $\mathrm{mg} \mathrm{L}$-ascorbic acid content $/ 100$ g raw material.

Total lycopene content was determined by high performance liquid chromatography methodology (HPLC) of Sadler et al. (1990) using the same instrumentation [mobile phase: methanol (Lab-Scan, Dublin, Ireland):tetrahydrofuran (Lab-Scan, Dublin, Ireland):water (Merck, Darmstadt, Germany) (67:27:6); flow rate: $2 \mathrm{ml} / \mathrm{min}$; detection at $472 \mathrm{~nm}$. All measurements were conducted in duplicate. The results from chromatographs were translated in $\mathrm{mg}$ total lycopene content /100 g raw material.

\section{Sensory analyses}

Sensory evaluation was carried out by a panel of five trained assessors. The assessors developed a list of profiling attributes and agreed on the following attributes: for appearance colour; for consistency firm and juicy and for taste fresh fruit taste intensity. The intensity of all sensory impressions was evaluated using a scale from 1 to 9 (1=low intensity and 9=high intensity). The panel also performed a preference/acceptance test using a 9-point hedonic scale.

\section{Results and Discussion \\ Osmotic pre-treatment}

A significant parameter characterizing osmotic dehydration is water loss. The water loss (WL) values for all cucumber samples pre-treated with oligofructose and HDM calculated according to Eq. 1 were demonstrated in Fig. 1.

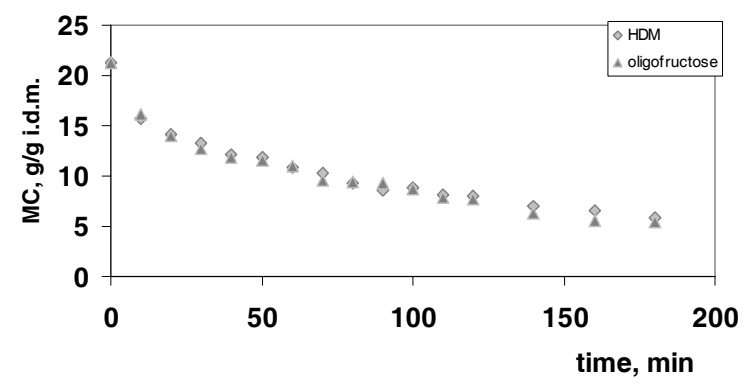

Fig. 1. Water loss during osmotic dehydration of cucumber tissue in oligofructose and HDM solution at temperature $35^{\circ} \mathrm{C}$

Under the same conditions solid gain (SG) of osmoactive substance depended on the kind of processed material. Differences were difficult to handle after short time of osmotic 
dehydration. The solid gain values for cucumber samples pre-treated with oligofructose and HDM calculated according to Eq. 2 were demonstrated in Fig. 2.

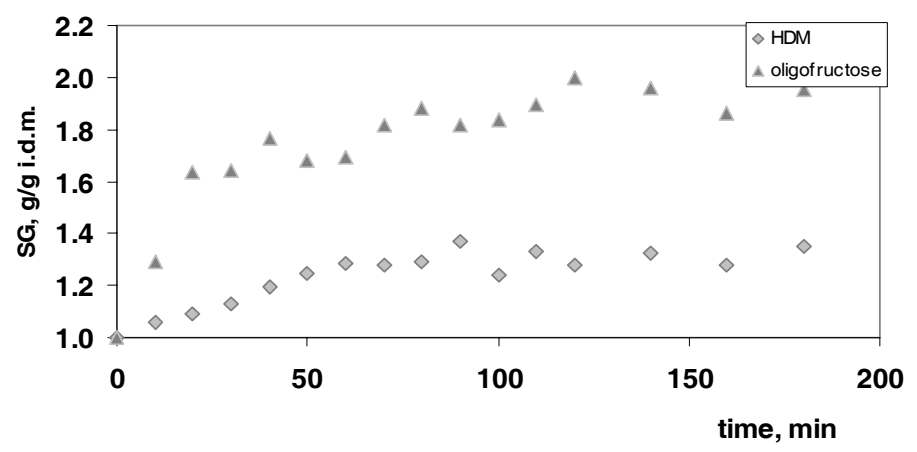

Fig. 2. Solid gain during osmotic dehydration of cucumber tissue in oligofructose and HDM solution at temperature $35^{\circ} \mathrm{C}$

The WL and SG values calculated from the Equations (1) and (2) after the osmotic pretreatment of cucumber, tomato and watermelon samples at $35^{\circ} \mathrm{C}$ for $60 \mathrm{~min}$, and strawberry samples for $150 \mathrm{~min}$, in the osmotic solutions of HDM and oligofructose are presented in Table 1. Treatments with all osmotic solutes caused a significant moisture loss from watermelon tissue. It can be noticed that the water loss values were similar for all treatments. The corresponding values for solid gain followed the same pattern. Based on this criterion, treatment with the selected osmotic solutes could be considered as "equivalent" procedures, explaining the selection of the specific duration - temperature combination used for each solute.

Table 1. Results of mass exchanges (WL, SG) after the osmotic pre-treatment of cucumbers, tomatoes and watermelon at $35^{\circ} \mathrm{C}$ for $60 \mathrm{~min}$, and strawberries for $150 \mathrm{~min}$, in $\mathrm{HDM}$ and oligofructose.

\begin{tabular}{ccccccccc}
\hline osmotic solute & \multicolumn{8}{c}{ plant sample } \\
\cline { 2 - 8 } & \multicolumn{9}{c}{ cucumber } & \multicolumn{2}{c}{ tomato } & strawberry & watermelon \\
\cline { 2 - 8 } & \multicolumn{9}{c}{ mass transfer kinetics (g of water/g initial dry matter) } \\
& WL & SG & WL & SG & WL & SG & WL & SG \\
\hline oligofructose & 12.00 & 1.80 & 7.48 & 1.27 & 2.75 & 0.60 & 4.77 & 0.43 \\
HDM & 11.75 & 1.25 & 8.42 & 1.20 & 3.00 & 0.40 & 4.76 & 0.44 \\
\hline
\end{tabular}

\section{Osmodehydrofreezing and Freezing}

\section{Texture}

Dehydration pre-freezing treatments are a useful tool to reduce or avoid the detrimental phenomena of loss of cellular structure and exudates loss at thawing, caused by the physical and chemical actions of freezing on fruit tissues (Huxsoll, 1982).

Based on texture measurements, firmness of osmotically pretreated with HDM and oligofructose plant samples were higher than the respective non treated when measured at time zero. After storage of the samples at $-20^{\circ} \mathrm{C}$ for 3,6 and 12 months, the firmness values were reduced. The change was more pronounced for the osmodehydrofrozen samples with HDM and oligofructose, however after a year of storage their firmness was still about higher than the corresponding values of the untreated. In Figure 3, the results for firmness values of untreated and pretreated watermelon and cucumber samples were presented. 

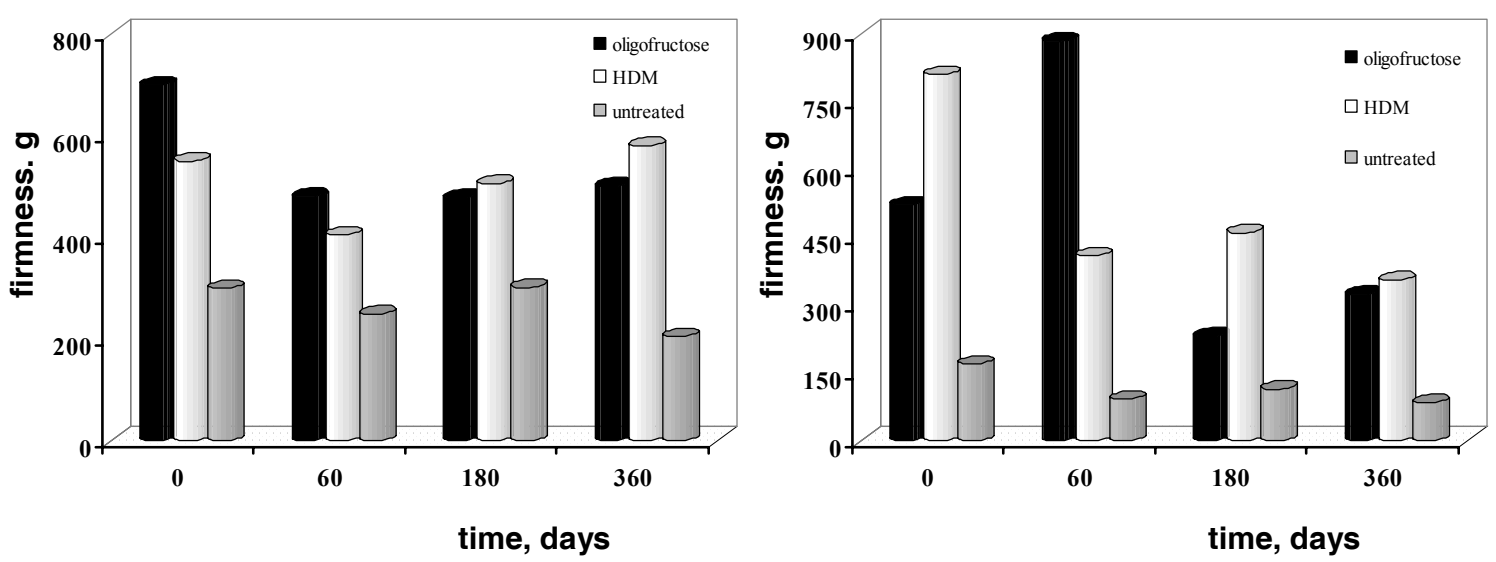

Fig. 3. Texture values (maximum forces: g) of thawed watermelon and cucumber samples, untreated and pre-treated with the osmotic solutes, oligofructose and HDM, and stored at temperature $-20^{\circ} \mathrm{C}$ for 12 months storage.

This increase in maximum force may be attributed to the effect of sugar uptake. This agrees with the report that presence of sugars increased firmness of thawed apple samples (Tregunno \& Goff, 1996). Torreggiani and Bertolo (2001) stated that cells protected by sugars exhibited less damage to the middle lamella and less severe shrinking of the cell content. Calcium chloride was also contributed to increased firmness due to the interaction of calcium with pectins and other cellular wall components of the plant cellular matrix (Gras et al., 2003). Fuchigami, Miyazaki and Hyakumoto (1995) observed that the worsened texture of frozen tomatoes was accompanied by a decrease in the content of pectic compounds. Lisiewska and Kmiecik (2000) also reported that the level of protopectins and pectins were significantly reduced by the freezing process itself and during subsequent frozen storage of tomato tissue. It can be concluded that the osmotic dehydration will result in dehydrated products of firm texture that can withstand further handling and processing.

Together with texture improvement, the penetration of solutes, combined with dehydration effect, could modify the fruit composition and improve pigment, colour, vitamin and aroma retention both during air dehydration and frozen storage.

\section{Colour}

The colour change of food samples was expressed by the appropriate parameter (Table 2).

Table 2. Colour parameters used for the expression of the colour change occurring during the frozen storage of untreated and pre-treated cucumber, tomato, strawberry and watermelon samples.

\begin{tabular}{cc}
\hline plant sample & colour parameter \\
\hline cucumber & $(\mathrm{DCmax}-\mathrm{DC}) /\left(\mathrm{DC}_{\mathrm{o}}-\mathrm{DC}\right)^{*}$ \\
tomato & $\mathrm{a}$ \\
strawberry & $(\mathrm{DCmax}-\mathrm{DC}) /\left(\mathrm{DC}_{\mathrm{o}}-\mathrm{DC}\right) *$ \\
watermelon & $\mathrm{DC}^{*}$ \\
\hline
\end{tabular}

* DC $=\sqrt{\left(a-a_{0}\right)^{2}+\left(b-b_{0}\right)^{2}}=$ chroma change $\left(\mathrm{a}, \mathrm{a}_{\mathrm{o}}\right.$ and $\mathrm{b}, \mathrm{b}_{\mathrm{o}}$ the values of $\mathrm{a}$ and $\mathrm{b}$ colour parameters at storage times $\mathrm{t}$ and zero) 
Colour change for untreated and pre-treated cucumber, strawberry and watermelon samples at temperature $-20{ }^{\circ} \mathrm{C}$ is shown in Fig. 4.
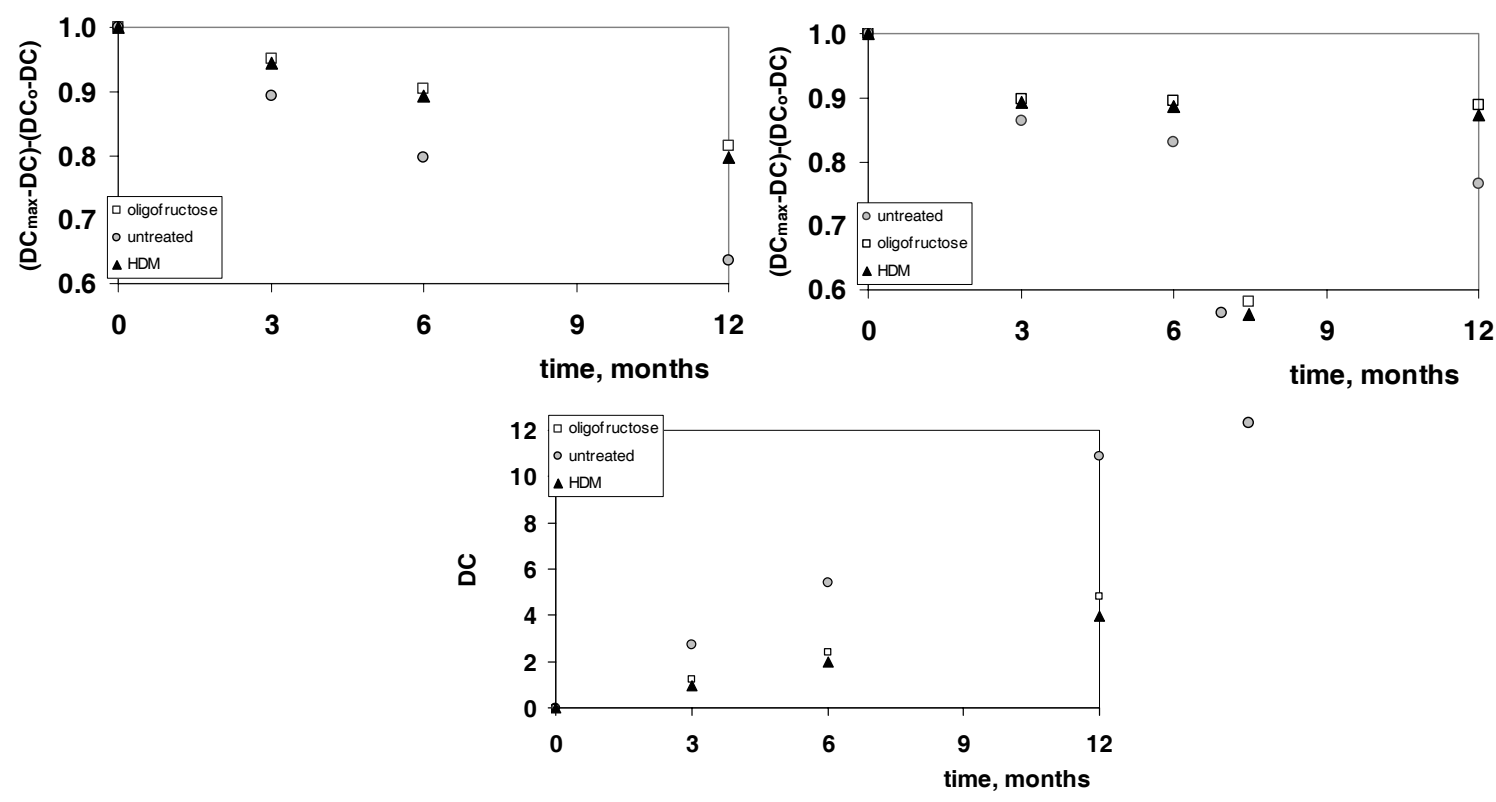

Fig. 4. Values for colour parameters (at 0 and after 3,6 and 12 months of storage at $-20^{\circ} \mathrm{C}$ ) of untreated and pre-treated cucumber, strawberry and watermelon samples with HDM and oligofructose.

\section{$\underline{\text { Vitamin C }}$}

Vitamin $C$ content of strawberry samples was measured to evaluate the effect of osmotic dehydration on the nutritional value of strawberry fruit. After the freezing process, during the subsequent frozen storage, strawberries and tomatoes exhibited a significant loss of Vitamin $\mathrm{C}$ at the temperatures studied (Fig. 5). In Fig. 5, the improved retention accomplished with the application of all osmotic pretreatments, is illustrated. After 12 months of storage at the temperature of $-20^{\circ} \mathrm{C}$, the osmodehydrofrozen samples retained better their vitamin content compared to the conventionally frozen, untreated strawberry and tomato samples.

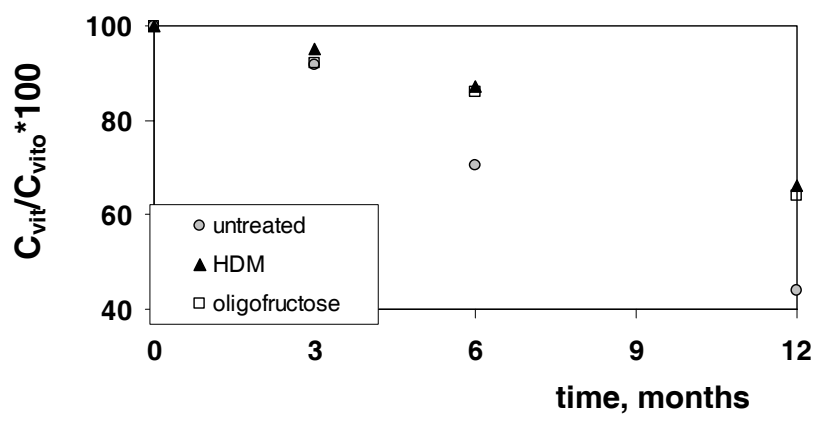

Fig. 5. Vitamin C loss of frozen tomato samples at $-20^{\circ} \mathrm{C}$ : untreated and pre-treated with HDM and oligofructose.

\section{Lycopene}


The lycopene loss is representatively shown in Fig. 6, for untreated conventionally frozen tomato and watermelon samples, and for samples pre-treated in the osmotic solution of HDM and oligofructose stored at temperatures, $-20{ }^{\circ} \mathrm{C}$. For all pre-treated samples the estimated rate of lycopene loss had lower values, compared to the corresponding rates for the untreated samples.
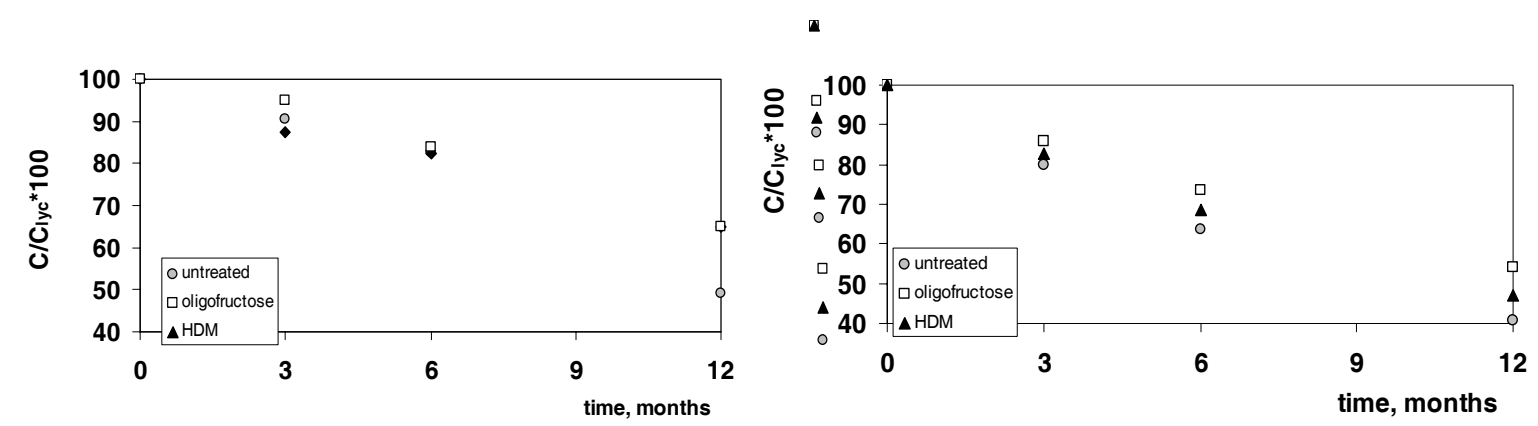

Fig. 6. Total lycopene loss of frozen tomato and watermelon samples at $-20^{\circ} \mathrm{C}$ : untreated and pre-treated with HDM and oligofructose.

Lycopene is the principal pigment found in tomatoes that also acts as an antioxidant by quenching free radicals during normal metabolism and may deactivate DNA chain-breaking agents that are implicated in some cancers (Shi et al., 1999). Watermelon is also a major source of lycopene among fruits (Fish and Davis, 2003).

Processing conditions such as high temperature, long processing time, light and oxygen have been shown to have effects on lycopene degradation. According to Shi, Le Maguer, Kakuda, Liptay and Niekamp (1999), in the osmotic treatment, the predominating mechanism is isomerization of lycopene. A possible explanation of this result is that sugar enters the tomato matrix and strengthen the binding force of lycopene in the tomato matrix. Osmotic solution (sugar) remaining on the surface layer of the tomato retards oxygen penetration and oxidation of lycopene. The osmotic treatment reduced lycopene losses in comparison to the other freezing methods. In this study, the osmotic pretreatment reduced the losses for all osmotic solutes used.

\section{$\underline{\text { Sensory properties }}$}

Sensory evaluation tests showed that colour, texture, taste and overall acceptance of all osmodehydrofrozen food samples were significantly improved, when compared to the respective quality features of conventionally frozen samples. Already, after the freezing process, at zero time of storage at $-20^{\circ} \mathrm{C}$, statistical differentiation was observed in the organoleptic quality of the frozen tissue. This confirmed the initial observation that colour and tissue integrity are well retained at osmotically pretreated samples. During frozen storage, untreated samples suffered from a detrimental texture and taste deterioration. For pretreated samples, taste is in most cases judged as 'pleasant and acceptable' despite differing from the traditional "tomato" organoleptic perception.

\section{Conclusion}

The application of osmotic pretreatment of foods caused substantial water loss and solid enrichment. Based on the comparative kinetic study of the quality degradation of frozen fruit and vegetables, the protective effect of the osmotic agent on vitamin $\mathrm{C}$, lycopene and color was demonstrated. The obtained sugar enrichment and partial water removal improved the sensory characteristics of treated samples (attractive appearance: bright color, good texture 
and pleasant taste) when compared to untreated ones. The untreated samples suffered from a detrimental texture and taste deterioration during storage.

The application of osmotic pre-treatment resulted in improved frozen product stability and extended shelf life.

\section{References}

Dermesonlouoglou, E.K., Giannakourou, M.C. and Taoukis, P.S. 2006. Kinetic modelling of the degradation of quality of osmo-dehydrofrozen tomatoes during storage. Food Chem. (in press)

Dermesonlouoglou, E.K., Giannakourou, M.C. and Taoukis, P.S. 2005. Stability of dehydrofrozen tomatoes pretreated with alternative osmotic solutes, J. Food Eng. (in press)

Dermesonlouoglou, E., Giannakourou, M.C., Taoukis, P.S. and Damikouka, I. 2003. Institute of Food Technologists (IFT) Annual Meeting, Chicago, 12-16/7.

Dermesonlouoglou, E., Giannopoulos, P., Giannakourou, M.C. and Taoukis, P.S. 2003. 12th

World Food Science and Technology Congress, Chicago, 16-20/7.

Ferrando, M., and Spiess, W.E.L. 2001. Journal of Food Engineering 49:115.

Fish, W.W. and Davis, A.R. 2003. Journal of Agricultural and Food Chemistry, 51(12), 35823585 .

Forni, E., Torreggiani, D., Battiston, P. and Polesello, A. 1986. Carbohydrate Polymers 6: 379.

Forni, E., Torreggiani, D., Crivelli, G., Maestrelli, A., Bertolo, G. and Santelli, F. 1990. Acta Hortuculturae 282:425.

Fuchigami, M., Miyazaki, K. and Hyakumoto, N. 1995. Journal of Food Science, 60, 132136.

Giannakourou, M.C. and Taoukis, P.S. 2002. Journal of Food Science, 67, 2221-2228.

Gingiacomo, R., Torreggiani, D. and Abbo, E. 1987. Journal of Food Processing and Preservation 11:183.

Gras, M.L., Vidal, D., Betoret, N., Chiralt, A. and Fito, P. 2003. Journal of Food Engineering, $56,279-284$.

Hawkes, J. and Flink, J.M. 1978. Journal of Food Processing and Preservation 2:265.

Huxsoll, C.C. 1982. Food Technology 5:98.

Lisiewska, Z. and Kmiecik, W. 2000. Food Chemistry, 70, 167-173.

Panagiotou, N.M., Karathanos, V.T. and Maroulis, Z.B. 1999. Drying Technology, 17(1\&2), 175-189.

Rao, V. 2001. Nutrition Research 21:843.

Sadler, G., Davis, J. and Dezman, D. 1990. Journal of Food Science, 55(5), 1460-1461.

Shi, J., Le Maguer, M., Kakuda, Y., Liptay, A. and Niekamp, F. 1999. Food Research International, 32, 15-21.

Sormani, A., Maffi, D., Bertolo, G. and Torreggiani, D. 1999. Food Science and Technology International 5(6):479.

Torreggiani, D. 1993. Food Research International 26:59.

Torreggiani, D., and Bertolo, G. 2001. Journal of Food Engineering 49:247.

Tregguno, N.B., and Goff, H.D. 1996. Food Research International 29:471.

Vidales, S., Alzamora, S.M., Bertolo, G., and Torreggiani, D. 2001. In J. Welti-Chanes (Ed.), Engineering and food for the 21st century, ICEF8. Lancaster, PA (USA):Technomic Publishing. 